\begin{tabular}{l|l} 
Jurnal Eksplorasi Akuntansi & $\begin{array}{l}\text { Vol. 2, No 4, Seri C, November 2020, Hal 3642-3655 } \\
\text { ISSN : 2656-3649 (Online) } \\
\text { http://jea.ppj.unp.ac.id/index.php/jea/issue/view/31 }\end{array}$
\end{tabular}

\title{
Pengaruh Retaliasi Dan Power Distance Terhadap Niat Melakukan Whistleblowing
}

\author{
Malwa Conella ${ }^{1}$, Sany Dwita ${ }^{2}$ \\ ${ }^{1}$ Alumni Juursan Akuntansi Fakultas Ekonomi Universitas Negeri Padang \\ ${ }^{2}$ Jurusan Akuntansi Fakultas Ekonomi Universitas Negeri Padang \\ *Korespondensi: malwaconella2611@gmail.com
}

\begin{abstract}
This study aims to test empirically about: 1) The effect of retaliation on the intention to do whistleblowing, 2) the effect of power distance on the intention to do whistleblowing. This type of research is classified as a quasi experiment. The data in the study were collected by distributing questionnaires online using google form to 152 accounting student class 2016 and 2017 from a university in the city of Padang. Data analysis was performed using ANOVA. The results of this study conclude that retaliation does not affect an individual in whistleblowing intentions, and power distance can affect an individual in whistleblowing intentions. This study focuses on the importance of the threat of retaliation to new employees in companies / public sector organizations, as well as the culture of an organization. This study uses accounting students as experimental subjects to examine the effect of retaliation and power distance on the intention to do whistleblowing.
\end{abstract}

Keywords: Retaliasi, Power Distance, Whistleblowing.

\section{How to cite (APA $6^{\text {th }}$ style):}

Conella, M., \& Dwita, S. (2020). Pengaruh Retaliasi Dan Power Distance Terhadap Niat Melakukan Whistleblowing. Jurnal Eksplorasi Akuntansi, 2(4), Seri C, 3642-3655.

\section{PENDAHULUAN}

Kecurangan (fraud) diakui sebagai salah satu masalah ekonomi yang serius di dunia (PBB, 2003). Kasus kecurangan (fraud) yang terungkap dalam beberapa tahun terakhir ini telah menjadi sorotan serius dari masyarakat, seperti korupsi yang menjadi salah satu kecurangan (fraud) yang paling sensitif (Marliza, 2018). Korupsi harus dihilangkan sebab akan menurunkan potensi kenaikan pertumbuhan ekonomi serta dapat menimbulkan kerugian negara. Salah satu cara yang efektif dalam menghilangkan tindakan korupsi yaitu dengan adanya tindakan whistleblowing (Cho dan Song, 2015).

Kasus-kasus mengenai whistleblowing telah banyak terjadi di Indonesia yang membuat masyarakat tercengang (Yaya, 2017). Salah satu kasus whistleblowing yang dilakukan oleh Fery Pasaribu, mantan General Manager Divisi Sistem Manajemen dan Informasi Teknologi PT Sarinah (Persero) yang sudah tiga kali membuat laporan dugaan korupsi. Kasus pertama tentang dugaan korupsi pada saat direksi periode 1996-2001, tapi tidak di tindaklanjuti. Kedua soal 
kerjasama dengan PT Graha Sari Pacific, pada saat masa kerja sama telah terjadi kerugian bangunan yang berada di atas tanah PT Sarinah yang sudah terlanjur dibongkar. Kasus terakhir yang diungkap oleh Ferry mengenai pembelian singkong kering. Direktur Utama PT Bumi Cassava, serta Manager Divisi Perdagangan PT Sarinah Persero, diduga melakukan penyimpangan pembelian singkong kering. Kerjasama itu ditaksir merugikan negara sebesar Rp 4,4 miliar. Pelaporan yang dilakukan oleh Ferry merupakan salah satu bentuk kecintaan terhadap Sarinah tempat ia bekerja selama 23 tahun, serta bentuk tanggungjawab sebagai ketua IKS. Akan tetapi laporan tersebut terbongkar ke Direksi Sarinah yang mengakibatkan Ferry diberhentikan secara paksa dengan alasan membocorkan rahasia perusahaan (CNN, 2015).

Selain kasus PT Sarinah, kasus whistleblowing lainnya yang terjadi di Indonesia adalah Kasus Agus Tjondro, yang mengungkap kasus suap kepada sejumlah anggota DPR dalam pemilihan Deputi Senior Gubernur BI, Murdiyanto. Agus Tjondro mengaku telah menerima cek pelawat (traveller cheque). Pengakuan tersebut menjadikan status Agus Tjondro sebagai saksi pelapor atau whistleblower dan juga berstatus sebagai tersangka. Kasus-kasus tersebut menunjukkan bahwa whistleblower rentan atas pembalasan dan minim perlindungan serta memperlihatkan kepada publik bahwa menjadi whistleblower dapat merugikan diri sendiri.

Whistleblowing menjadi topik penting ketika ada keterlibatan praktik akuntansi (Emerson et al., 2017) dan memiliki pengaruh jangka panjang terhadap organisasi perusahaan untuk meningkatkan keefektifannya (Near dan Miceli, 1985). Taylor dan Curtis (2013) dalam penelitiannya menjelaskan bahwa literatur akademis cukup banyak membahas whistleblowing dalam organisasi, akan tetapi sejumlah pertanyaan tetap muncul mengenai bagaimana menerapkan mekanisme pelaporan yang efektif dan mengapa mekanisme-mekanisme yang memenuhi semua kriteria yang disarankan tidak selalu memperoleh laporan dari kegiatan tidak etis yang dilihat.

Penelitian whistleblowing sebagian besar difokuskan pada tiga faktor yang mempengaruhi pelaporan: (a) faktor individu, seperti demografi, gender, kepribadian, usia, jenis kelamin, pengembangan moral (Chiu, 2003; Ekmen dkk, 2014); (b) faktor organisasi, seperti kebijakan pengungkapan internal, kode etik, sistem kompensasi, serta aksi dan retaliasi (Puni dan Anlesinya, 2017; Magnus et al., 2005; Wong-On-Wing dan Lui, 2013) dan (c) faktor situasional, seperti intensitas moral, keseriusan kesalahan, tingkat ambiguitas kesalahan, posisi whistleblower yang relatif rendah dari perilaku kesalahan (Keenan, 2000; Darjoko dan Nahartyo, 2017; Priyastiwi dan Halim, 2017). Pemahaman tentang proses menjadi rumit karena kompleksitas variabel dan interaksi diantara variabel-variabel tersebut (Sims dan Keenan, 1998).

Selain dari beberapa faktor tersebut, keputusan untuk menjadi whistleblowing dipengaruhi oleh banyak faktor, salah satunya adalah faktor budaya (Finandari dan Wijayanto, 2016). Pengaruh budaya sangat alami dan otomatis sehingga pengaruhnya terhadap perilaku sering diterima begitu saja. Penelitian selanjutnya memerlukan identifikasi mengenai dari faktor-faktor tersebut seperti faktor organisasi dan faktor budaya (Taylor dan Curtis, 2013). Hal tersebut mengundang peneliti untuk menguji faktor organisasi dan faktor budaya terhadap niat melakukan whistleblowing, mengingat belum banyaknya penelitian yang meneliti faktor organisasi dan faktor budaya secara bersamaan.

Beberapa penelitian terdahulu menunjukkan bahwa kemungkinan retaliasi terhadap whistleblowing penting dalam menjelaskan keputusan seseorang untuk terlibat dalam whistleblowing (Keenan, 1995; Liyanarachchi dan Newdick, 2009; Miceli dan Near, 1994, 2002). Menurut penelitian Near dan Miceli (1994) menyatakan bahwa retaliasi tidak secara konsisten terkait dengan ketergantungan organisasi pada wrongdoing atau kekuatan whistleblower, berbeda dengan penelitian yang dilakukan oleh Near dan Miceli (1986) yang mengatakan bahwa retaliasi 
secara konsisten terkait dengan ketergantungan organisasi pada kekuatan whistleblower. Penelitian selanjutnya diperlukan untuk menentukan apakah penting untuk membedakan sumber retaliasi atau untuk memperluas definisi retaliasi karena menurut penelitian Near dan Miceli (1994) jika prediktor retaliasi dapat didefinisikan mungkin organisasi dapat melakukan upaya untuk menghindari retaliasi.

Retaliasi didefinisikan sebagai bentuk paksaan atau konsekuensi bagi whistleblower untuk menutup mulut mereka ketika mengetahui adanya penipuan atau kecurangan (fraud) dalam suatu organisasi (Magnus dan Viswesvaran, 2005). Retaliasi merupakan sebuah bentuk tuntutan yang dilakukan oleh rekan kerja atau manajer terhadap karyawan yang telah melaporkan adanya pelanggaran disuatu instansi dan tuntutan tersebut muncul akibat konsekuensi melakukan whistleblowing (Joy, 2014). Miceli dan Near (1989) menyatakan bahwa efek dari retaliasi terhadap whistleblowing menunjukkan hasil yang beragam. Oleh karena itu, keputusan seseorang melakukan whistleblowing kemungkinan akan dipengaruhi oleh retaliasi.

Setiap organisasi mempunyai budaya yang berbeda-beda dan telah mengakar pada diri organisasi tersebut. Budaya tersebut dapat mempengaruhi perilaku seseorang (Puni dan Anlensinya, 2017). Beberapa penelitian lintas budaya dalam akuntansi mengacu pada dimensi nilai oleh Hofstede. Menurut dimensi Hofstede (2011) ada enam indeks untuk mengukur dimensi budaya disetiap negara yaitu; power distance, individualism, masulinity, uncertainity avoidance, long term orientation, dan indualgence.

Penelitian tentang power distance sebagian besar digunakan untuk menjelaskan perbedaan perilaku antar budaya, kontras persepsi power distance dari peran yang sama di berbagai negara. Power distance didefinisikan sebagai sejauh mana anggota lembaga dan organisasi yang kurang kuat dalam suatu organisasi mengharapkan dan menerima bahwa kekuasaan didistribusikan secara tidak merata (Hofstede, 2005). Power distance adalah adanya jarak kekuasaan antara atasan dengan bawahan, power distance kerap dirasakan oleh bawahan terhadap atasan. Power distance kebanyakan timbul karena adanya perbedaan jabatan, kekuasaan, kemampuan finansial dikarenakan atasan memiliki kekuatan superior yang lebih tinggi dibandingkan dengan bawahan dan sering kali terjadi di instansi pada umumnya (Santoso, 2019). Dengan demikian, kesimpulan yang dapat ditarik dari definisi power distance adalah adanya jarak kekuasaan antara atasan dengan bawahan karena kekuasaan didalam organisasi didistribusikan secara tidak merata.

Penelitian ini diharapkan dapat berkontribusi untuk pengembangan teori mengenai whistleblowing dengan menjelaskan retaliasi dan power distance yang diduga dapat mempengaruhi keputusan whistleblowing yaitu implementasi dari theory of planned behavior. Lebih dalam lagi, penelitian ini diharapkan juga memberikan kontribusi dalam menciptakan budaya organisasi yang efektif dalam pengungkapan kecurangan di dalam organisasi dengan teori keadilan sebagai penjelas. Berdasarkan uraian tersebut, maka peneliti memberi judul penelitian ini sebagai "Pengaruh Retaliasi dan Power Distance Terhadap Niat Melakukan Whistleblowing".

\section{REVIEW LITERATUR DAN HIPOTESIS Theory of Planned Behavior}

Theory of planned behavior (TPB) merupakan pengembangan lebih lanjut dari theory of reasoned action (TRA). Ajzen (1991) menyatakan bahwa theory of planned behavior (TPB) dapat menjelaskan faktor-faktor yang mempengaruhi individu dalam berperilaku. Sejauh ini, teori yang paling sering diterapkan pada penelitian dengan keterkaitan antara sikap, niat, dan perilaku adalah theory of planned behavior.

Menurut Mahyami (2013), alat yang dapat digunakan untuk memprediksi perilaku individu ketika individu tersebut tidak memiliki kontrol kemauan sendiri secara penuh adalah 
theory of planned behavior. The theory of planned behavior secara khusus cocok untuk menjelaskan niat pelapor dalam hal mengungkapkan kecurangan, karena whistleblowing adalah tindakan yang dilakukan berdasarkan pada proses psikologis yang sangat kompleks (Gundlach dkk., 2003 dalam Park dan Blenkinsopp, 2009).

Ofstad (1961) dalam Blenkinsp dan Edwards (2008) mengatakan bahwa seseorang telah membuat keputusan berarti mereka telah melakukan satu dari tiga hal, yaitu: (1) memulai serangkaian perilaku reaksi yang mendukung sesuatu; (2) memutuskan untuk melakukan tindakan tertentu, yang tidak diragukan lagi harus dia lakukan; atau (3) membuat keputusan tentang apa yang harus dilakukan seseorang dalam situasi tertentu setelah mempertimbangkan beberapa tindakan alternatif. Randall dan Gibson (1991) dalam Park dan Blenkinsopp (2009) menerapkan TPB untuk memprediksi pengambilan keputusan etis pada profesi medis dan melaporkan bahwa teorinya berhasil menjelaskan maksud untuk melaporkan kesalahan.

\section{Teori Keadilan}

John Rawls adalah tokoh yang pertama kali mengemukakan teori keadilan. Keadilan (justice) adalah pandangan yang muncul ketika seseorang mendapatkan sesuatu yang mereka dan orang-orang di sekitarnya berhak memilikinya (Cohen dalam Pinder, 1998 dalam Runing, 2011). Seseorang akan peduli dengan apa yang akan mereka terima tetapi juga peduli pada apa yang orang lain terima. Sesuatu yang dapat diterima ini dapat berupa manfaat atau akibat atau juga outcome yang sifatnya non-moneter seperti status dan tanggung jawab.

Teori keadilan merupakan konsep keadilan tentang keharusan mendistribusikan nilai-nilai sosial dalam individu secara fair atau adil agar dapat memberikan manfaat pada semua pihak yang terlibat dan berdasarkan pada kesepakatan bersama yang telah disetujui. Menurut teori ini, setiap kontribusi yang diberikan individu kepada organisasi seharusnya dibalas dengan imbalan yang proposional agar memberikan kepuasan pada diri kontributor.

Teori keadilan memiliki potensi untuk berkontribusi pada implementasi mekanisme pengaduan yang efektif karena penelitian telah menunjukkan hubungan positif antara dimensi keadilannya dan perilaku pro-sosial (Seifert dan Sweeney, 2010). Karyawan meyakini bahwa mereka diperlakukan secara adil oleh atasan mereka lebih mungkin untuk membingkai hubungan sebagai pertukaran sosial timbal balik, memajukan perilaku yang dimaksudkan untuk mendapatkan manfaat organisasi, seperti whistleblowing (Seifert dan Sweeney, 2010).

\section{Whistleblowing}

Whistleblowing didefinisikan sebagai pengungkapan oleh anggota organisasi (mantan atau masih menjadi anggota) atas suatu praktik-praktik ilegal, tidak bermoral, atau legitimasi dibawah kendali pimpinan kepada individu atau organisasi yang dapat menimbulkan efek tindakan perbaikan (Near dan Miceli, 1985). Seseorang yang melakukan tindakan whistleblowing disebut dengan whistleblower.

Whistleblowing melibatkan anggota aktif atau mantan organisasi yang melaporkan tindakan kecurangan, tidak bermoral, atau tidak sah di bawah kendali pemimpin organisasi untuk pihak yang bersedia dan mampu mengambil tindakan memperbaiki kesalahan (Keenan, 1992). Whistleblowing adalah urusan yang sangat penting karena faktanya banyak pelanggaran publik dan korporasi tidak pernah dipublikasikan dan pelaporan dari whistleblower terbukti lebih bermanfaat dalam mengungkapkan kecurangan daripada pemeriksaan internal/eksternal dan kontrol (Bhargava dan Mandala, 2014).

Beberapa tahun terakhir whistleblowing sering dikaitkan dengan profesi akuntan. Profesi akuntan telah banyak terlibat dalam skandal yang terjadi di perusahaan terkhusus akuntan yang 
berperan sebagai auditor. Beberapa penelitian telah menjelaskan faktor-faktor yang menyebabkan akuntan/auditor memilih atau tidak memilih untuk menjadi whistleblower, faktor-faktor tersebut seperti faktor individu, faktor situasional, faktor organisasi, dan faktor demografi (Chiu, 2003; Ekmen dkk., 2014; Keenan, 2000; Darjoko dan Nahartyo, 2017; Puni dan Anlesinya, 2017; Taylor dan Curtis, 2013 dan Wong-On-Wing dan Lui, 2013).

\section{Retaliasi}

Retaliasi dapat didefinisikan sebagai bentuk paksaan atau konsekuensi bagi whistleblower untuk menutup mulut mereka ketika mengetahui adanya penipuan atau kecurangan dalam suatu organisasi (Magnus dan Viswesvaran, 2005). Retaliasi adalah hasil dari suatu konflik yang terjadi antara organisasi dan karyawan, dimana anggota organisasi tersebut berusaha untuk mengendalikan karyawan dengan mengancam akan mengambil, atau benar-benar mengambil tindakan yang akan dapat merugikan kesejahteraan karyawannya karena telah melaporkan adanya tindakan yang dianggapnya salah, melalui saluran internal maupun eksternal (Regh et al., 2008).

Greenberger et al. (1987) dalam Saputra dan Dwita (2018) mengatakan bahwa retaliasi hadir dalam dua kondisi yaitu retaliasi tinggi (penalty) dan retaliasi rendah (affiliation). Penalty mengacu pada konsekuensi disiplin dalam bentuk ancaman terhadap individu atau property, tuntutan hukum, pemutusan hubungan kerja, dan penjara. Affiliation mengacu pada bentuk hubungan dengan orang lain di dalam atau luar organisasi, yaitu individu lainnya yang tunduk pada retaliasi daripada whistleblower (Greenberger et al., 1987).

Retaliasi dapat dilakukan dalam berbagai bentuk, mulai dari upaya pemaksaan terhadap whistleblower untuk menarik tuduhan melakukan kesalahan hingga pengecualian langsung dari whistleblower di organisasi (Parmerlee et al., 1982). Tindakan retaliasi dapat mencakup langkahlangkah yang diambil organisasi untuk melemahkan proses pengaduan, isolasi whistleblower, pencemaran nama baik atas whistleblower, penghapusan penghasilan tambahan, dan bentuk diskriminasi atau pelecahan lainnya (Parmerlee et al., 1982).

\section{Power Distance}

Power distance didefinisikan sebagai sejauh mana anggota lembaga dan organisasi yang kurang kuat dalam suatu organisasi mengharapkan dan menerima bahwa kekuasaan didistribusikan secara tidak merata (Hofstede, 2005). Power distance merupakan sejauh mana individu menerima perbedaan pangkat, status, hak istimewa, dan kekuasaan dalam masyarakat (Rao dan Pearce, 2016).

Afriana (2017) menjelaskan bahwa hakikatnya dari hubungan atasan dan bawahan adalah adanya perbedaan kekuasaan. Taylor dan Curtis (2013) dalam penelitiannya menjelaskan bahwa power distance memiliki dua bentuk, power distance rendah dan power distance tinggi. Power distance rendah menunjukkan adanya kesetaraan antara atasan dan bawahan dalam kekuasaan, tidak takut menghadapi atasan, dan tidak menerima perbedaan jabatan. Sedangkan, power distance tinggi menunjukkan perbedaan secara luas antara atasan dan bawahan serta memberikan penghormatan kepada atasan secara besar.

Goodwin (1999) menyatakan bahwa power distance membawa implikasi etis yang penting. Power distance tinggi dapat menyebabkan seseorang tidak akan menantang perilaku tidak etis dari atasan, sementara power distance rendah kemungkinan akan mendorong individu untuk menantang perilaku yang tidak etis tersebut dengan adanya tindakan whistleblowing (Curtis et al., 2012).

Studi Taylor dan Curtis (2013) yang menguji variabel power distance terhadap whistleblowing menemukan bahwa lebih cenderung untuk melaporkan rekan mereka daripada 
atasan mereka. Hal ini sejalan dengan penelitian Puni dan Anlesinya (2017) yang menguji masyarakat dengan power distance tinggi terhadap kecenderungan whistleblowing di Afrika kemudian menemukan bahwa power distance tinggi meningkatkan persepsi negatif terhadap whistleblowing, maka dari itu whistleblower masih dipandang sebagai pengkhianat bukan pahlawan.

\section{Hipotesis}

Berdasarkan kerangka pemikiran penelitian dan teori yang ada maka peneliti menduga bahwa:

H1: Individu yang menghadapi potensi retaliasi yang rendah akan lebih cenderung menunjukkan niat melakukan whistleblowing dibandingkan individu yang menghadapi potensi retaliasi tinggi.

H2: Individu yang berada pada power distance rendah akan menunjukkan niat melakukan whistleblowing yang berbeda dengan individu yang berada pada power distance tinggi.

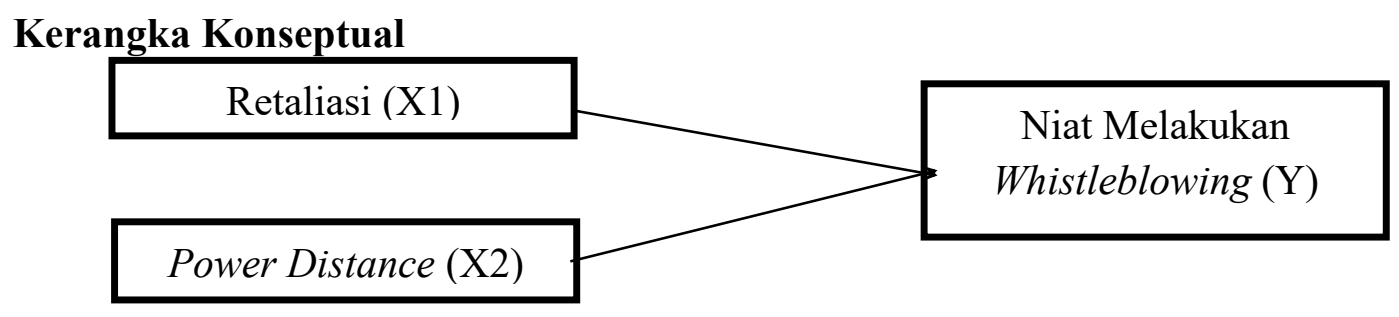

\section{Gambar 1. Kerangka Konseptual}

\section{METODE PENELITIAN}

\section{Jenis Penelitian dan Sumber Data}

Penelitian ini menggunakan data kuantitatif. Jenis data yang diperoleh dari penelitian ini merupakan data subjek. Data subjek (selfreport data) adalah data penelitian yang dilaporkan sendiri oleh responden secara individual atu kelompok berupa sikap, opini, pengalaman/karakteristik. Sumber data yang digunakan dalam penelitian ini adalah data primer. Data primer merupakan data yang diperoleh langsung dari sumber pertama seperti perorangan atau individu.

\section{Desain Penelitian}

Penelitian ini menggunakan pendekatan kuantitatif dan termasuk jenis penelitian kausatif, serta menggunakan data primer yang dikumpulkan melalui jenis metode penelitian kuasi eksperimen. Desain kuasi eksperimen adalah desain yang mempunyai kelompok kontrol tetapi tidak dapat berfungsi secara penuh untuk mengontrol variabel-variabel luar (extraneous variabels) yang dapat mempengaruhi pelaksanaan kuasi eksperimen (Sugiyono, 2013; Cooper dan Schindler, 2014).

Desain kuasi eksperimen yang digunakan dalam penelitian ini adalah desain factorial $2 \times 2$. Variabel independen terdiri dari retaliasi dan power distance. variabel retaliasi dimanipulasi menjadi retaliasi tinggi dan retaliasi rendah. Sedangkan power distance dimanipulasi menjadi power distance tinggi dan power distance rendah. 
Tabel 1.

Desain Faktorial $2 \times 2$

\begin{tabular}{|l|l|l|l|}
\hline \multicolumn{2}{|c|}{} & \multicolumn{2}{|c|}{ Power Distance } \\
\cline { 3 - 4 } \multicolumn{2}{|c|}{} & Tinggi & Rendah \\
\hline \multirow{3}{*}{ Retaliasi } & Tinggi & WSB 1 & WSB 3 \\
\cline { 2 - 4 } & Rendah & WSB 2 & WSB 4 \\
\hline
\end{tabular}

\section{Populasi dan Sampel}

Penelitian ini menggunakan mahasiswa jurusan akuntansi Strata I di Fakultas Ekonomi Universitas Negeri Padang angkatan 2016 dan 2017 sebagai partisipan. Alasan peneliti memilih mahasiswa sebagai sampel dalam penelitian ini adalah karena mahasiswa cukup relevan dijadikan subjek penelitian eksperimentasi.

Populasi pada penelitian ini adalah mahasiswa akuntansi S1 angkatan 2016 dan 2017 yang berjumlah 152. Penentuan jumlah sampel menurut Surakhmad (1994) dalam Riduwan (2010:65) dapat dirumuskan sebagai berikut:

Keterangan:

$\mathrm{S}=$ Jumlah sampel yang diambil

$\mathrm{n}=$ Jumlah anggota populasi

Pada penelitian ini untuk jumlah anggota populasi sebanyak 152 orang mahasiswa, maka jumlah minimum sampel pada penelitian ini adalah: Setelah dilakukan perhitungan untuk menentukan jumlah sampel diatas, maka jumlah minimal yang digunakan dalam penelitian ini adalah $152 \times 47,9 \%=72,8=73$ responden.

\section{Instrumen Penelitian}

Instrumen pada penelitian ini merupakan pengadopsian dari Arnold dan Ponemon (1991). Instrumen tersebut telah pernah dijui oleh peneliti terdahulu di New Zealand seperti Liyanarachchi dan Newdick (2009) dan di Australia seperti Liyanarachchi dan Adler (2011) dan di Indonesia seperti Saputra (2018) dan Ayuningtyas (2018) dengan menggunakan tiga skenario yang telah diterjemahkan dari Bahasa Inggris ke Bahasa Indonesia. Sebelum melakukan penelitian, peneliti akan melakukan uji coba pada mahasiswa angkatan 2016 karena memiliki karakteristik yang sama dengan responden yang akan diteliti. Uji coba bertujuan untuk memberikan gambaran apakah instrumen yang digunakan bisa dipahami oleh responden dan agar peneliti mendapat instrumen yang layak digunakan.

Instrumen penelitian ini terdiri dari IV bagian. Bagian I berisi kata pengatar dari peneliti. Bagian II berisi data untuk mendapatkan info demografi partisipan. Bagian III berisi penjelasan secara umum tentang variabel yang diteliti. Bagian IV dan $\mathrm{V}$ berisi skenario pendek tentang retaliasi dan power distance.

Skenario pada penelitian ini diadopsi dari Liyanarachchi (2009). Ilustrasi retaliasi dibagi menjadi retaliasi tinggi dan rendah berasal dari penelitian Greenberger et al, (1987), dan ilustrasi power distance dibagi menjadi power distance tinggi dan rendah berasal dari penelitian Taylor dan Curtis (2013). Bentuk manipulasi dirancang dengan menggambarkan ilustrasi whistleblowing yang realistis. Untuk menggambarkan variabel retaliasi, responden diberikan skenario dengan mengilustrasikan responden sebagai staf/karyawan di kantor pemerintah daerah yang memeriksa akun biaya perjalanan dinas. Staf/karyawan (responden) menemukan adanya kesalahan 
klasifikasi terhadap bukti-bukti biaya hotel yang mengatas namakan kepala bidang di kantor pemerintahan tersebut. Akhirnya menunjukkan adanya ketidaksesuaian bahwa biaya hotel tersebut tidak termasuk kedalam kebijakan penggantian dari biaya hotel perjalanan dinas. Staf/keuangan (responden) melaporkan hal ini kepada kepala badan di kantor pemerintahan tersebut. Namun, justru mendapatkan ancaman akan dimutasikan ke posisi non-job, dan tidak akan menerima kenaikan jabatan, jika tetap melaporkan kepada kepala badan sebagai bentuk retaliasi tinggi. Konsekuensi retaliasi rendah berupa pendapat atau ide yang disampaikan oleh staf/karyawan tersebut akan diterima atau didengarkan oleh kepala badan.

Untuk menggambarkan variabel power distance, responden diberikan skenario dengan mengilustrasikan responden sebagai kepala bidang disalah satu kantor pemerintah daerah yang melakukan perjalanan dinas. Kabid (rekan kerja) adalah responden. Kabid (rekan kerja) responden, telah bertugas sebagai staf keuangan di kantor pemerintahan salah satu pekerjaanya adalah memeriksa akun biaya perjalanan dinas. Pada suatu hari kabid (rekan kerja) responden terkejut ketika dia mengajukan pergantian atas biaya hotel perjalanan dinas yang sudah dilakukan. Hasil pemeriksaan menunjukkan bahwa telah ditemukan bukti-bukti biaya hotel sebesar Rp5.000.000,- atas nama kabid (rekan kerja) tanpa penjelasan yang lengkap. Kabid (rekan kerja) akan diminta memproses penggantian biaya hotel perjalanan dinas tanpa perlu membahas masalah lebih lanjut. Namun, masalah ini ingin diproses lebih lanjut dengan cara melaporkan kepada Kepala Badan. "Untuk power distance tinggi, atasan berperan sebagai pelaku kecurangan, sedangkan untuk power distance rendah rekan kerja yang berperan sebagai pelaku kecurangan".

Uji manipulasi dilakukan untuk memastikan bahwa responden telah memahami skenario kasus dan manipulasi yang sudah diberikan sudah realistik dan dapat dipahami. Pengecekan manipulasi untuk retaliasi dilakukan dengan mengajukan pertanyaan: "Apakah Adi akan dimutasi ke posisi non-job, tidak akan menerima promosi jabatan, serta tidak di anggap tidak bisa dipercaya jika melaporkan temuan pelanggaran?". Sedangkan pengecekan manipulasi untuk power distance dilakukan dengan mengajukan pertanyaan:" Siapakah yang melakukan pelanggaran?" Responden yang dikatakan lulus uji manipulasi apabila merespon sesuai dengan kasus yang telah diberikan dengan mencentang salah satu pilihan.

\section{Prosedur Penelitian}

Pembagian, pengisian, dan pengembalian kuesioner dilakukan secara online menggunakan google form. Terlebih dahulu peneliti akan membuat grup melalui aplikasi whatsapp yang berisikan mahasiswa akuntansi 2016 dan 2017 dengan tujuan untuk memudahkan pembagian kuesioner dan mempermudah koordinasi dengan partisipan. Selanjutnya peneliti memperkenalkan diri kepada responden. Kemudian peneliti akan memberikan penjelasan secara umum mengenai tujuan dari penelitian ini serta sikap dan peran yang akan dimainkan oleh para responden. Setelah penjelasan mengenai tata cara pelaksanaan penelitian, peneliti akan mengirimkan link dari google form yang akan diisi oleh responden.

\section{Pengukuran Variabel}

Tiga variabel diteliti dalam penelitian ini, yaitu: variabel niat melakukan whistleblowing sebagai variabel dependen; variabel retaliasi sebagai variabel independen dan; variabel power distance sebagai variabel indenpenden. Retaliasi dan power distance dapat mempengaruhi niat seseorang dalam melakukan whistleblowing.

Variabel whistleblowing merupakan pengungkapan informasi yang dilakukan oleh anggota (sebelumnya dan saat ini) di dalam organisasi atas praktik ilegal, tidak bermoral, atau tidak sah dibawah kendali atasan mereka kepada individu atau organiasi yang mungkin dapat 
mengambil tindakan efek perbaikan. Pengukuran variabel whistleblowing dalam instrument penelitian ini dilakukan dengan melihat pilihan jawaban responden pada kuesioner dalam skala likert 1-7 ( 1 = sangat tidak mungkin, 7 = sangat mungkin $)$.

Variabel retaliasi adalah suatu tindakan yang tidak menyenangkan berupa kehilangan pekerjaan, dikucilkan, dianggap pengkhianat, tidak dapat dipercaya dan pencabutan fasilitas atau individu dalam bekerja yang diterima oleh whistleblower sebagai konsekuensi langsung terhadap tindakan pelaporan atas suatu pelanggaran/kesalahan baik secara internal maupun eksternal. Variabel retaliasi diukur dengan membagi partisipan menjadi dua perlakuan yang dimanipulasi yaitu retaliasi tinggi dan rendah. Dua skenario berbeda menjelaskan masing-masing retaliasi yang berbeda juga. Retaliasi ini diukur dengan menggunakan skala nominal dimana retaliasi kuat diberi simbol angka 1 dan retaliasi rendah diberi simbol angka 2.

Variabel power distance adalah adanya jarak kekuasaan antara atasan dengan bawahan yang ditimbulkan karena adanya perbedaan jabatan, kekuasaan, kemampuan finansial dikarenakan atasan memiliki kekuatan superior yang lebih tinggi dibandingkan oleh bawahan dan sering kali terjadi di instansi pada umumnya. Variabel power distance merupakan variabel yang dimanipulasi. Variabel ini diukur dengan membagi partisipan menjadi dua perlakuan yang dimanipulasi yaitu power distance rendah dan power distance tinggi. Skala nominal digunakan dengan skor 1 untuk power distance tinggi dan skor 2 untuk power distance rendah.

\section{HASIL DAN PEMBAHASAN}

Data dalam penelitian ini dikumpulkan melalui penyebaran kuesioner dengan menggunakan media google form. Penyebaran kuesioner dilakukan kurang lebih 2 minggu, dengan menyebarkan kepada mahasiswa Akuntansi tahun masuk 2016 dan 2017 FE UNP yang telah peneliti kumpulkan di grup whatsapp. Kuesioner yang sudah diisi langsung masuk keg mail peneliti yang memudahkan peneliti untuk mengetahui berapa terisi. Peneliti memberikan beberapa kali peringatan ke grup whatsapp kepada responden, sehingga peneliti mendapatkan tingkat pengembalian kuesioner yang cukup tinggi untuk selanjutnya dilakukan pengelolahan data. Jumlah responden yang dikatakan lulus uji manipulasi adalah sebanyak 103 orang dari total sebanyak 152 partisipan yang mengisi dan mengembalikan kuesioner. Berikut merupakan ringkasan dari penyebaran data dalam penelitian ini.

Sebelum peneliti melakukan olah data atas hasil dari penyebaran kuesioner, peneliti terlebih dahulu melakukan pemeriksaan terhadap skenario apakah lolos uji manipulasi dan bisa diolah. Berdasarkan kriteria uji manipulasi yang ditetapkan sebelumnya, maka dapat dikumpulkan 103 kuesioner yang dapat diolah dan 49 kuesioner tidak lolos uji manipulasi. Hal ini dikarenakan responden mungkin dalam keadaan tidak nyaman sehingga kurang berkonsentrasi dan kurang memahami skenario perlakuan yang diberikan. Sehingga dapat disimpulkan bahwa angka response rate yang diperoleh pada penyebaran kuesioner penelitian adalah sebesar 67,76\% atau 103 kuesioner.

Sebelum data diolah dengan ANOVA maka perlu dilakukan uji asumsi klasik dilakukan bertujuan untuk mendapatkan keyakinan bahwa data dalam penelitian layak atau tidak untuk dilakukan pengolahan data secara lebih lanjut. Uji asumsi klasik dalam penelitian ini terdiri dari uji normalitas dan uji homogenitas. 
Tabel 2. Hasil Uji Normalitas dan Homogenitas

\begin{tabular}{|c|r|r|c|}
\hline \multicolumn{4}{|c|}{ Levene's Test of Equality of Error Variances } \\
\hline \multicolumn{3}{|c|}{ Variabel Dependen: Niat Melakukan Whistleblowing } \\
\hline F & df1 & df2 & Sig. \\
\hline 2,090 & 3 & 99 & 0,106 \\
\hline
\end{tabular}

Sumber: Data primer yang diolah, 2020

Tabel 2 digunakan untuk menguji hipotesis nol yang menyatakan bahwa variance dari grup dalam penelitian ini adalah sama (merupakan asumsi dari ANOVA). Jadi dalam hal ini table 2 menguji apakah variance dari delapan skenario manipulasi secara signifikan berbeda. Hasil nilai $\mathrm{F}$ sebesar 2,090 dengan signifikansi 0,106 yang jauh di atas $0,05(p>0,05)$. Sehingga dapat disimpulkan bahwa tidak dapat menolak hipotesis nol (tidak signifikan) atau dengan kata lain variance dari ke delapan skenario manipulasi adalah sama (memenuhi asumsi ANOVA).

Teknik analisis data yang digunakan untuk menguji kebeneran hipotesis yang diajukan adalah analisis uji ANOVA (Analysis of Variance). ANOVA merupakan salah satu uji komparatif yang digunakan untuk menguji perbedaan mean (rata-rata) dan lebih dari dua kelompok. Ada dua jenis ANOVA yaitu satu arah atau one-way ANOVA dan dua arah atau two-way ANOVA. Hipotesdan kedua dalam penelitian ini melakukan pengujian dengan uji analisis varians one-way ANOVA. ANOVA satu arah menguji satu-persatu dari masing-masing variabel $\mathrm{X} 1$ atau variabel $\mathrm{X} 2$ terhadap Y, sedangkan ANOVA dua arah menguji secara bersama-sama variabel X1 dan X2 terhadap Y. Berikut ini merupakan ringkasan hasil uji ANOVA.

Tabel 3. Hasil Uji Hipotesis

\begin{tabular}{|c|c|c|c|c|c|c|}
\hline \multicolumn{7}{|c|}{ Variabel Dependen: Niat Melakukan Whistleblowing } \\
\hline & Source & $\begin{array}{l}\text { Sum of } \\
\text { Squares }\end{array}$ & Df & $\begin{array}{l}\text { Mean } \\
\text { Square }\end{array}$ & $\mathrm{F}$ & Sig. \\
\hline Model & Corrected & $53,670^{\mathrm{a}}$ & 2 & 26,835 & 29,181 & 0,000 \\
\hline & Intercept & 3068,954 & 1 & 3068,954 & 3337,228 & 0,000 \\
\hline & Retaliasi & 2,681 & 1 & 2,681 & 2,916 & 0,091 \\
\hline & PWD & 53,345 & 1 & 52,345 & 56,920 & 0,000 \\
\hline & Error & 91,961 & 100 & 0,920 & & \\
\hline & Total & 3223,000 & 103 & & & \\
\hline Total & Corrected & 145,631 & 102 & & & \\
\hline
\end{tabular}

Sumber: Data primer yang diolah 2020

\section{Perbedaan pengaruh retaliasi terhadap niat melakukan whistleblowing.}

Hasil pengujian hipotesis menunjukkan tidak ada perbedaan pengaruh retaliasi tinggi dan retaliasi rendah terhadap niat melakukan whistleblowing. Hal ini dapat dilihat dari hasil pengelolahan data menggunakan uji one-way ANOVA. Hasil tabel menunjukkan F hitung sebesar 2,916 dan diperkuat dengan nilai signifikansi yang diperoleh sebesar 0,091>0,05.

Retaliasi diduga akan berpengaruh positif terhadap niat melakukan whistleblowing karena hasil dari konflik antar organisasi dan karyawannya, dimana dari konflik tersebut, organisasi berusaha mengontrol karyawan dengan mengancam untuk mengambil tindakan atau benar-benar mengambil tindakan yang merugikan kesejahteraan dari karyawannya, sebagai respon atau balasan atas pelaporan yang dilakukan oleh karyawan (Regh et al., 2008). Pada penelitian ini jika 
individu berada dalam situasi retaliasi yang rendah akan lebih cenderung menunjukkan niat melakukan whistleblowing daripada individu yang berada dalam situasi retaliasi tinggi ditolak karena tidak memiliki pengaruh perbedaan yang signifikan antara tingkat retaliasi rendah dan tingkat retaliasi tinggi. Berdasarkan hasil penelitian ini, baik dalam kondisi retaliasi tinggi maupun retaliasi rendah, pengaruhnya tidak signifikan untuk seorang whistleblower melakukan tindakan whistleblowing. Hal tersebut disebabkan karena ketidakberanian akan risiko yang ditimbulkan apabila melakukan tindakan whistleblowing.

Efendi dan Nuraini (2019) menyatakan bahwa retaliasi terjadi dikarenakan adanya dorongan atas keinginan organisasi untuk membuat whistleblower diam (menutup mulut ketika mengetahui adanya kecurangan dalam organisasi), mendiskreditkan whistleblower, mencegah pihak luar mengetahui, dan mencegah whistleblower melakukan tindakan yang lain. Hasil penelitian ini dukung oleh penelitian Efendi dan Nuraini (2019), yang menilai pengaruh retaliasi terhadap intensi whistleblowing pada mahasiswa Universitas Negeri di Aceh, hasil penelitian tersebut menyebutkan bahwa retaliasi tidak berpengaruh terhadap whistleblowing. Hasil ini didukung oleh hasil penelitian yang dilakukan Istyanti (2017), Ayuningtyas (2018) dan Ridwan (2013) yang menemukan bahwa retaliasi tidak memiliki pengaruh terhadap whistleblowing.

\section{Perbedaan pengaruh power distance terhadap niat melakukan whistleblowing}

Hasil dari pengujian hipotesis kedua menunjukkan bahwa tidak ada perbedaan pengaruh power distance tinggi dan power distance rendah terhadap niat melakukan whistleblowing. Hal ini dapat dilihat dari hasil pengolahan data menggunakan uji one-way ANOVA. Hasil tabel menunjukkan $\mathrm{F}$ hitung sebesar 56,920 dan diperkuat dengan nilai signifikansi yang diperoleh sebesar $0,000<0,05$.

Hasil penelitian ini memberikan kesimpulan bahwa individu yang berada pada power distance rendah dianggap lebih memiliki keberanian atau suka terhadap tantangan ketika melihat suatu temuan kesalahan dibandingkan power distance tinggi yang lebih memikirkan risiko yang akan dihadapinya dalam lingkungan pekerjaan. Karyawan lebih bersedia melaporkan rekan kerja mereka, karena tekanan dari teman sebaya tidak cukup untuk menekan perilaku whistleblowing. Namun, seperti diteorikan power distance tinggi yang ada di perusahaan tampaknya menghasilkan tekanan kepatuhan, dibuktikan dengan adanya keengganan karyawan untuk melaporkan atasan. Karyawan lebih sering berinteraksi dengan manajer daripada mitra karena itu karyawan bisa mengamati perilaku yang dilakukan manajer (perilaku buruk) yang dapat mengancam kualitas perusahaan.

Sejalan dengan penelitian Taylor dan Curtis (2013), Puni dan Anlesinya (2017) dan Wong-On Wing dan Lui (2010) bahwa budaya power distance mempengaruhi keputusan untuk melakukan whistleblowing. Budaya yang kekuasaannya terdistribusi secara tidak merata membuat hierarki kekuasaan mengerucut sehingga pada lapisan paling bawah merasa ada tekanan ketika hendak melaporkan atasan.

Karyawan yang hanya memiliki tujuan untuk memenuhi standar profesional secara teknis dengan melaporkan kecurangan yang dlihatnya, tetapi takut untuk melaporkan kecurangan tersebut karena pelakunya adalah manajer/atasan, dapat mengurangi kemungkinan pengaduan pada suatu organisasi. Oleh sebab itu, perusahaan dapat membentuk budaya organisasi yang tidak mencerminkan adanya jarak kekuasaan dan perusahaan memicu karyawan untuk ikut berpartisipasi mewujudkan organisasi yang bebas dari tindak kecurangan melalui tindakan whistleblowing. 


\section{KESIMPULAN, KETERBATASAN DAN SARAN \\ Kesimpulan}

Berdasarkan hasil temuan penelitian dan pengujian hipotesis yang telah dilakukan dapat disimpulkan bahwa individu yang berada pada power distance rendah akan menunjukkan niat melakukan whistleblowing berbeda dengan individu yang berada pada power distance tinggi.

\section{Keterbatasan}

Penelitian ini memiliki keterbatasan antara lain sebagai berikut:

1. Subjek penelitian adalah mahasiswa akuntansi tahun 2016 dan 2017 Fakultas Ekonomi Universitas Negeri Padang yang diasumsikan secara kognitif dapat berperan sebagai akuntan/auditor, sehingga hasil penelitian ini tidak dapat digeneralisasikan untuk setiap kondisi.

2. Penelitian kuasi eksperimen ini menggunakan skenario sebagai ilustrasi dalam dunia nyata, keterbatasan skenario ini karena mengandung bias yang tidak bisa sepenuhnya sesuai dengan kondisi di lapangan.

3. Responden dalam penelitian kuasi eksperimen ini sebagian kecil kurang memahami prosedur penelitian ini yang dijelaskan melalui sugesti perlakuan/treatment yang peneliti berikan, sehingga sebagian kecil tidak lolos uji manipulasi.

4. Penelitian di Indonesia yang meneliti mengenai variabel independen pada penelitian ini masih terbatas, sehingga menyulitkan peneliti untuk mencari referensi dan menyamakan keadaan antara luar negeri dan dalam negeri.

\section{Saran}

Berdasarkan penelitian ini maka bisa diajukan beberapa saran yang dihasilkan dari penelitian ini:

1. Peneliti selanjutnya diharapkan dapat memberikan perlakuan/treatment terhadap responden kuasi eksperimen secara lebih baik dan merancang prosedur yang efektif sehingga memicu responden dalam mengerjakan kuesioner serta responden dapat memahami dengan baik perlakuan/treatment yang diberikan dan lolos uji manipulasi

2. Peneliti selanjutnya yang ingin meneliti ulang mengenai retaliasi dapat mempertimbangkan

3. Peneliti selanjutnya agar dapat menggunakan variabel independen lain yang mungkin memiliki pengaruh terhadap niat melakukan whistleblowing seperti identifitas professional, personal cost, tingkat keseriusan kecurangan, komitmen organisasi, dan pertimbangan etis.

4. Peneliti selanjutnya juga diharapkan meneliti mengenai interaksi ketiga faktor whistleblowing yaitu faktor organisasi, hukum, dan individu agar menghasilkan informasi yang lebih layak dan lebih luas mengenai whistleblowing.

\section{DAFTAR PUSTAKA}

Ajzen, I. (1991). The Theory of Planned Behavior. Organizational behavior and human decision processes. $50.179-211$.

Afriana, R. \& Odiatma, F. (2017). Pengaruh personal cost reporting, status wrongdoer dan keseriusan kesalahan terhadap whistleblowing intention. Jurnal Akuntansi Keuangan dan Bisnis. 10(1), 11-20.

Bhargava, Nimisha \& Madala, Mani K. (2014). An overview of whistleblowing status in various continents across the world. International journal of management and social sciences research (IJMSSR). 3(10).

Blenkisopp, J dan Edwards, M. S. (2015). Chapter 8 on On Not Blowing The Whistle: Quiescent Silence As An Emotion Episode. Emotions, Ethics and Decision-Making. 4, 181-206. 
Chiu, R. K. (2003). Ethical Judgement and whistleblowing intention : examining the moderating role of locus control. Journal of Business Ethics. 43, 65-74.

CNN Indonesia. (2019). Kronologi kasus jiwasraya, gagal bayar hingga dugaan korupsi. Diakses pada 10 September 2020 dari https://m.cnnindonesia.com

Cohen-Charash, Y., \& Spector, P. (2001). The role of justice in organizations: A meta-analysis. Organizational Behavior and Human Decision Processes, Vol.86: 278-321.

Cooper, D. R., and Pamela S. S. (2014). Business Research Methods. Twelfth Edition. Florida Atlantic University: McGraw-Hill Companies, inc.

Darjoko, Felix J dan Nahartyo, E. (2017). Efek tipe kecurangan dan anonimitas terhadap keputusan investigasi auditor internal atas tuduhan whistleblowing. Jurnal Akuntansi dan Keuangan Indonesia. 14(2), 202 - 221.

Finandari, D dan Titis W. (2016). Analisis pengaruh dimensi budaya terhadap niat melakukan whistleblowing perbandingan antara mahasiswa dan engineer. Jurnal Teknosains. 6(1), 44-52.

Greenberger, David B. et al. 1987. Oppositions and Group Norms: The Reciprocal Influence of whistleblowers ad co- workers. Journal of business ethic, 6, 527-542.

Hofstede, G. H. (2011). Dimensionalizing cultures: The hofstede model in context. Online Readings in Psychology and Culture, 2(1) at

Hofstede, I. (2019). Country Comparison. Diakses pada 22 Februari 2020 dari https://www.hofstede-insights.com/country-comparison/indonesia/

Joy, Amy Block. (2014). Retaliation: Case study on prevention strategies. Faculty of Emeritus and Author, University Of California Davis.

Keenan, John P et al. (1992). Whistleblowing: a conceptualization and model. Academy of Management Journal, 1

Keenan, John P. (2002). Whistleblowing: A Study of managerial differences. Employee Responsibilities and rights Journal, 14(1).

Liyanarachchi, G \& Milne M. (2005). Comparing the investment decisions of accounting practitioners and student: An empirical study on the adequancy of students surrogates. Accounting Forum. 121-135.

Liyanarachchi, G dan Newdick C. (2009). The Impact of Moral Reasoning and Retaliation on Whistle Blowing: New Zealand Evindence. Journal of Business Ethics. 89, 37-57.

Magnus-Mesmer, J. and C. Viswesvaran. (2005). Whistleblowing in Organizations: An Examination of Correlates of Whistleblowing Intentions, Actions, and Retaliation. Journal of Business Ethics .62, 277-297.

Marliza, Resi. (2018). Pengaruh Personal Cost of Reporting, Komitmen Organisasi, dan Tingkat Keseriusan Kecurangan Terhadap Niat Melakukan Whistleblowing (Studi Empiris pada Organisasi Perangkat Daerah Kota Payakumbuh). E-Journal Universitas Negeri Padang. 6(1).

Miceli, M. P et al. (1999). Can Laws protect whistleblowers? Result of a naturally occurring field experiment. Work and Occupations. 26(1): 129-151.

Near, J. P. dan Miceli, M. P. (1996). Whistleblowing: myth and reality. Journal of management. 22(3), 507-526.

Near, J. P. dan Miceli, M P. (2008). Review of public personnel administration. 28(3).

Park, H dan Blenkinsopp, J. (2009). Whistleblowing as Planned Behavior- A Survey of South Korean Police Officers. Journal of Business Ethics. 85, 545-556.

Parmerlee, Marcia A, dkk. (1982). Correlations of Whistleblowers' Perceptions of Organizational Retaliation. Adminitrative Science Quarterly. 27(1), 17-34. 
Perserikatan Bangsa-Bangsa (PBB). (2003). United Nations Convention Against Corruption. New York: United Nations.

Priyastiwi. (2017). Pengaruh Faktor Demografi dan Iklim Organisasi Terhadap Niat Whistleblowing Internal. Jurnal Riset Manajemen, 4 (1), 12-22.

Puni, Albert dan Anlesinya, Alex. (2017). Whistleblowing Propensity in Power Distance Societies. Journal of Global Responsibility, 29, 564-578

Rao, A. N. and Pearce, J. L. (2016). Should management practice adapt to cultural values? The evidence against power distance adaptation. Cross Cultural \& Strategic Management, 23 (2), 257-286.

Regh, Michael T, dkk. (2008). Antecedents and outcomes of retaliation against whistleblowers: Gender differences and power relationship. Journal of organization science,19(2), 221240.

Riduwan. (2010). Metode dan Teknik Menyusun Tesis. Bandung: Alfabeta.

Runing, Hunik. (2011). Jarak Kekuasaan sebagai Pemoderasi Pengaruh Keadilan Organisasional Terhadap Komitmen Karyawan pada Supervisor. Jurnal Manajemen Teori dan Terapan,4(3).

Saputra, Bagus \& Dwita, Sany. (2018). Pengaruh retaliation dan gender terhadap niat melakukan whistleblowing. Jurnal WRA, 6(2).

Seifert, D. L., J. T. Sweeney, J. A. Joireman, and J. M. Thornton. (2010). The influence of organizational justice on accountant whistleblowing. Accounting, Organizations and Society, 35, 707-717.

Sims, Randi L dan Keenan, J. P. (1998). Predictors of external whistleblowing Organizational and intrapersonal variables. Nova Southasterm University.

Sugiyono. (2011). Metode Penelitian Kuantitatif, Kualitatif dan R \& D. Bandung: Alfabeta.

Taylor, E. Z., \& Curtis, M. B. (2013). Whistleblowing in audit firms : organizational response and power distance. Behavioral Research in Accounting, 25(2), 21-43.

Wong-On-Wing, Bernard dan Lui, Gladie. (2013). Beyond cultural values: An implicit they approach to cross-cultural research in accounting ethics. American Accounting Association, $25(1), 15-36$.

Yaya, R. L. (2017). Whistleblowing dan faktor-faktor yang mempengaruhi niat melaksanakannya oleh aparatur sipil negara. Jurnal Akuntansi. 21( 03), 336-350. 